\title{
Teorias Etiológicas do Transtorno de Personalidade Borderline: da neurobiologia à epigenética
}

\author{
Etiological Theories of Borderline Personality Disorder: from neurobiology to epigenetics \\ Teorías Etiológicas del Trastorno Límite de la Personalidad: de la neurobiología a la epigenética
}

Recebido: 13/02/2021 | Revisado: 21/02/2021 | Aceito: 23/02/2021 | Publicado: 02/03/2021

Luiz Guilherme Figueira Honorio

ORCID: https://orcid.org/0000-0002-5729-9758

Universidade Anhanguera Uniderp, Brasil

E-mail: FigueiraLuizGuilherme@gmail.com

Mateus Kenzo Sanches Kuwakino

ORCID: https://orcid.org/0000-0002-2388-8765

Universidade Anhanguera Uniderp, Brasil

E-mail: rapaccia14@gmail.com

José Carlos Souza

ORCID: https://orcid.org/0000-0003-4460-3370

Universidade Estadual de Mato Grosso do Sul, Brasil

E-mail: josecarlossouza@uol.com.br

\begin{abstract}
Resumo
Objetivo: identificar as possíveis anomalias neurobiológicas e epigenéticas, assim como os efeitos do trauma durante a infância na patogênese do Transtorno de Personalidade Borderline (TPB). Metodologia: para a revisão narrativa, utilizou-se a PubMed, Scielo, UpToDate como base de dados, no período entre 2010 e 2020, resultando em 688 artigos, dos quais 26, distintos por critérios de inclusão, serviram de base para este estudo. Resultados: em neurobiologia, anormalidades foram encontradas, entretanto os estudos não conseguiram comprovar se tais modificações originam o transtorno ou são decorrentes da psicopatologia, enquanto na genética metilações aberrantes de genes - candidatos ou por seleção genômica ampla (GWS)- podem estar ligados a etiologia do TPB. Por fim, a análise dos artigos acerca TPB e trauma infantil revelou que uma porcentagem significativa dos indivíduos com o transtorno sofreu abuso ou indiligência na infância. Considerações finais: a teoria que combina a neurobiologia, a epigenética e o ambiente se mostrou a mais plausível para explicar a etiologia do TPB. Dito isso, mais estudos devem ser realizados a fim de compreender tanto se esses achados são patognômicos do transtorno ou consequências dele, quanto as correlações anatômicas e funcionais, genéticas e ambientais para a patogênese do TPB.
\end{abstract}

Palavras-chave: Etiologia; Transtorno de Personalidade Borderline; Neurobiologia; Epigenética; Trauma infantil.

\begin{abstract}
Objective: To identify the possible neurobiological and epigenetic anomalies, as well as the effects of childhood trauma on the pathogenesis of Borderline Personality Disorder (BPD). Methodology: PubMed, Scielo and UpToDate were used for the narrative review, done with papers published between 2010 and 2020, resulting in 688 articles, of which 26, distinguished by inclusion criteria, served as the basis for this study Results: in neurobiology, abnormalities were found, however the studies could not prove whether such modifications originate the disorder or are due to psychopathology, whereas in genetics aberrant methylations of genes - candidates or by broad genomic selection (GWS)- may be linked to TPB etiology. Finally, the analysis of the articles about BPD and childhood trauma revealed that a significant percentage of individuals with BPD suffered abuse or neglect in childhood. Final considerations: the theory combining neurobiology, epigenetics and the environment proved to be the most plausible to explain the etiology of BPD. More studies should be carried out to understand both whether these findings are pathogenic to the disorder or its consequences, and the anatomical, functional, genetic, and environmental correlations for the pathogenesis of BPD.
\end{abstract}

Keywords: Etiology; Borderline Personality Disorder; Neurobiology; Epigenetics; Child trauma.

\section{Resumen}

Objetivo: identificar las posibles anomalías neurobiológicas y epigenéticas, así como los efectos del trauma durante la infancia en la patogénesis del Trastorno Límite de la Personalidad (TLP). Metodología: para la revisión narrativa, se utilizó Pubmed, Scielo, Uptodate como base de datos, en el período entre 2010 y 2020, resultando en 688 artículos, de los cuales 26, distintos por criterios de inclusión, sirvieron de base para este estudio. Resultados: en neurobiología, anomalías fueron encontradas, sin embargo, los estudios no consiguieron comprobar si tales modificaciones originan el trastorno o son resultantes de la psicopatología, mientras que en la genética metilaciones aberrantes de genes - 
candidatos o por selección genómica amplia (GWS)- pueden estar ligados a la etiología del TLP. Finalmente, el análisis de los artículos sobre TLP y trauma infantil reveló que un porcentaje significativo de los individuos con el trastorno sufrió abuso o descuido en la infancia. Consideraciones finales: la teoría que combina la neurobiología, la epigenética y el ambiente se ha mostrado la más plausible para explicar la etiología del TLP. Dicho esto, más estudios deben ser realizados para comprender tanto si estos hallazgos son patógenos del trastorno o consecuencias de este, como las correlaciones anatómicas, funcionales, genéticas y ambientales para la patogénesis del TLP. Palabras clave: Etiología; Trastorno Límite de la Personalidad; Neurobiología; Epigenética; Trauma infantil.

\section{Introdução}

De acordo com o DSM-5, o Transtorno de Personalidade Borderline (TPB) é caracterizado por um padrão generalizado envolvendo distúrbios de autoimagem, instabilidade emocional, flutuações de humor, instabilidade e hipersensibilidade perante relações interpessoais e impulsividade (American Psychiatric Association, 2014).

O TPB é um problema que afeta entre 1,6\% da população em geral (Skodol, 2020) sendo que estudos não clínicos realizados nos EUA relataram a prevalência ao longo da vida em 5,9\% dos casos, enquanto outros estudos em ambientes clínicos expuseram a presença do TPB para pacientes urbanos de cuidados primários, pacientes psiquiátricos ambulatoriais e pacientes psiquiátricos internados, respectivamente em 6,4\%, 9,3\% e 20\% dos casos (Skodol, 2020).

Ainda que se entenda a importância clínica para esta patologia, as bases etiológicas não são bem definidas. A maioria das teorias sugerem uma etiologia resultante da combinação de fatores neurobiológicos, epigenéticos e psicossociais. Achados em neuroimagem relataram alterações anatômicas e funcionais na biologia neurológica, como disfunções da amígdala, nos neurotransmissores serotonérgicos, gabaérgicos e dopaminérgicos, e em neurotrofinas. Outros estudos encontraram fatores genéticos no surgimento do transtorno, assim como a possível hereditariedade da psicopatologia. E por fim, situações traumáticas e/ou estressoras podem configurar a expressão do TPB - em especial, quando ocorrem na infância e adolescência podendo estar, inclusive, associados à prevalência do Transtorno de Personalidade Borderline ao longo da vida.

Faz-se necessária, portanto, uma compreensão ampla dos fatores que podem compor a etiologia do TPB. No presente estudo, busca-se, por meio de uma revisão de literatura, descrever os principais mecanismos e anomalias neurobiológicas, as possíveis implicações genéticas até então descobertas e os principais eventos psicossociais, com enfoque àqueles ocorridos na infância com teor traumático. Com isso, assimilar as causas e as correlações entre os fatores etiológicos com o surgimento e a prevalência do Transtorno de Personalidade Borderline (TPB).

Nesse contexto, o estudo tem como objetivo discutir as teorias etiológicas do Transtorno de Personalidade Borderline, relacionadas a neurobiologia, à epigenética e ao trauma na infância.

\section{Metodologia}

Com o intuito de produzir esta revisão narrativa acerca das etiologias do Transtorno de Personalidade Borderline - a partir evidências que investigassem as origens neurobiológicas e epigenéticas dos efeitos do trauma infantil e até mesmo da interrelação entre esses fatores -foram utilizados os seguintes descritores: "Borderline"; "Neurobiology"; "Epigenetics" e "Childhood trauma", além do operador booleano "AND" e o cruzamento de pares entre os descritores. Foram descartados estudos que não abordassem a patogênese do transtorno. Utilizou-se o método quali-quantitativo, em que houve complementariedade do método qualitativo, no qual há uma importante interpretação por parte do pesquisador para análise dos fenômenos envolvidos no estudo, e do método quantitativo, com enfoque na coleta de dados número, em especial porcentuais para o presente estudo (Pereira et al., 2018). A busca foi realizada nas bases de dados UpToDate, PubMed e Scielo.

A base de dados MEDLINE via PubMed (PMC) é o arquivo digital gratuito do U.S. National Institutes of Health (NIH) de periódicos das áreas de biomedicina e ciências da vida. Enquanto o UpToDate é uma base de dados privada que utiliza dos conceitos da medicina baseada em evidências, trazendo um acervo em diversas áreas médicas, com suas 
informações e recomendações submetidas a um extenso processo de avaliação em pares. E, por fim, a base de dados Scielo (Scientific Electronic Library Online) que é uma base de dados voltada para a publicação de artigos, em especial de países da América Latina e Caribe. As plataformas de dados foram consultadas independente de seu idioma de origem, assim como as publicações as quais foram analisadas em âmbito nacional e internacional.

\section{Resultados}

Foram utilizados os recursos disponíveis, sobre Transtornos de Personalidade e Transtorno de Personalidade Borderline, encontrados na plataforma de dados UpToDate <https://www.uptodate.com/>, assim como as definições utilizadas no DSM-V - Manual Diagnóstico e Estatístico de Transtornos Mentais e no CID-10 - Classificação Estatística Internacional de Doenças e Problemas Relacionados à Saúde.

Além disso, obteve-se na plataforma de dados PubMed 684 artigos, dentre eles, 135 do cruzamento em pares "Borderline" e "Neurobiology", 144 "Borderline" e "Epigenetics", e com a maioria dos achados somando, 405 resultados do cruzamento "Borderline" e "Childhood trauma". Na plataforma de dados Scielo foram encontrados 4 artigos. Configurando, assim, um total de 688 artigos.

Do total de artigos encontrados, aplicou-se um filtro temporal, pré-selecionando os artigos publicados nos últimos 10 anos, com isso foram descartadas 234 publicações por apresentarem datação anterior ao ano de 2010. Após filtragem, realizouse uma nova avaliação, com a leitura apenas do resumo de cada artigo, utilizando critérios de inclusão que favorecessem publicações com enfoque na etiologia do TPB nos aspectos neurobiológicos, epigenéticos e nas relações da infância. Dessa forma, foram selecionados 26 artigos, que compõem este trabalho.

Com a amostragem estabelecida, apresentar-se-ão os dados obtidos pela leitura do título, resumo e texto completo, com o compromisso de averiguar a confiabilidade da metodologia, do número de amostras e dos achados, e de contrapor os resultados com o intuito de aumentar a veracidade deles, a seguir, serão apresentados os tópicos da discussão.

\section{Discussão}

\subsection{Neurobiologia e Transtorno de Personalidade Borderline (TPB)}

É possível compreender a manifestação do TPB, desde o desenvolvimento à sua sustentação, por diversos fatores neurobiológicos (Ruocco \& Carcone, 2016). Entretanto, mesmo com os avanços técnicos e tecnológicos, os estudos mostram resultados heterogêneos, incluindo conclusões ambíguas e até mesmo contraditórias. As principais investigações podem se basear em alterações neuroendócrinas - sistema serotonérgico e eixo hipotalâmico-hipofisário-adrenérgico (HPA) -, alterações morfofuncionais, em especial na amígdala, no córtex cingulado anterior (ACC), no córtex pré-frontal dorsolateral (DLPFC) e no córtex orbitofrontal (OFC), e na distribuição de substância cinzenta e substância branca.

Distúrbios no sistema serotonérgico podem estar diretamente ligados à sintomatologia do TPB, com a análise do potencial de ligação ao receptor de 5-HT2A e do aprisionamento de metil-L-triptofano, utilizando PET, concluíram-se dois achados: (1) Esse receptor é expresso em neurônios piramidais de regiões que podem sofrer alterações anatômicas e funcionais em pacientes que possuem TPB - incluindo ACC, córtex-frontal, córtex-insular, córtex-orbital, córtex-parietal e córtex entorrinal -, e (2) que há influência do gênero: identificou-se nos homens com TPB uma menor síntese de serotonina nos giros frontal medial, cingulado anterior e temporal superior e no corpo estriado; enquanto isso, nas mulheres com TPB, menos áreas foram afetadas e estas apresentaram maior potencial de ligação ao receptor 5-HT2A nos gânglios da base e nos córtices occipital e temporal medial, além da presença de ligação de paroxetina plaquetária inferior a 50\% (Ruocco \& Carcone, 2016; Wingenfeld, Spitzer, Rullkötter \& Lowe., 2010). 
O eixo hipotalâmico-hipofisário-adrenérgico (HPA) é responsável por coordenar a resposta fisiológica ao estresse. Esse eixo é regulado via hipotálamo e hipocampo, e tem como produto a biossíntese de cortisol. Estudos de imagem, envolvendo ressonância magnética e morfometria baseada em Voxel encontraram uma diminuição no volume do hipocampo bilateralmente em pacientes TPB, sugerindo o trauma no início da vida e efeitos resultantes do cortisol como possíveis fatores causais da redução volumétrica, sendo mais grave em pacientes com histórico de trauma infantil autorrelatados (Ruocco \& Carcone, 2016; Wingenfeld et al., 2010). Somado a isso, as pesquisas não chegaram em um consenso quanto à atividade do eixo HPA e a liberação de cortisol. Alguns estudos indicam supressão de cortisol e aumento da inibição do feedback do eixo HPA (Chanen \& Kaess 2012), enquanto outros mostram uma produção excessiva de cortisol e hiperatividade do eixo HPA (Leichsering, Leibing, Kruse, New \& Leweke, 2011). Além disso, ensaios neuroendócrinos de linha de base indicam um aumento no nível da atividade basal do eixo HPA em TPB (Ruocco \& Carcone, 2016). Sendo assim, anormalidades no sistema límbico podem explicar alguns sintomas ou até mesmo a etiologia do TPB. Em contrapartida, não está claro se esses achados são uma causa, consequência ou epifenômeno da psicopatologia, necessitando de estudos futuros que visem elucidar quando e como funcionam essas anormalidades (Chanen \& Kaess, 2012).

Investigações com uso de ressonância magnética e morfometria baseada em Voxel indicaram reduções volumétricas na amígdala. Uma tentativa de explicar essa anomalia sugeriu um polimorfismo no gene promotor 5-HTR1A no córtex cingulado anterior (ACC), no córtex pré-frontal dorsolateral (DLPFC) e no córtex orbitofrontal (OFC), além da redução do hipocampo já citada (Chanen \& Kaess, 2012; Ruocco \& Carcone, 2016). Outro relato incluiu a diminuição em 6,2\% do lobo frontal (Guendelman \& Garay \& Mine, 2014). Ao expor pacientes TPB a situações estressoras, envolvendo simulação de abandono e de abuso, constatou-se um aumento do fluxo sanguíneo em regiões do DLPFC e uma falha ao ativar o giro cingulado anterior e o OFC, em relação ao grupo controle (Wingenfeld et al, 2012). O estudo, ao ser realizado sobre a memória autobiográfica forneceu uma série de disfunções nos pacientes TPB, incluindo uma hiperatividade da amígdala, de áreas préfrontais e regiões fronto-límbicas - dentre elas, o ACC. Entretanto, trabalhos que envolvem emoções são limitados quanto à amostragem e subjetividade dos participantes, dificultando a veracidade dos resultados (Wingenfeld et al, 2012), enquanto as demais anomalias estruturais se defrontam com a mesma problemática da análise do eixo HPA; ou seja, não se esclarece, novamente, se essas modificações são a etiologia ou um efeito do TPB.

A disponibilidade de substância cinzenta e branca está sendo investigada em pacientes TPB, com o intuito de encontrar diferenças com indivíduos não portadores de TPB. Uma diminuição volumétrica de substância cinzenta e aumento da substância branca rostral e subgenual foram relatadas por Goodman, Mascitelli e Triebwasser (2013). Já Guendelman et al. (2014) relataram aumento da concentração de substância cinzenta na amígdala direita, em contrapartida a uma menor concentração dessa na região subgenual esquerda. Regiões como giros temporais médios bilaterais, hipocampos bilaterais e giro frontal inferior, entre outros também apresentaram diminuição da substância cinzenta. A região motora suplementar direita, o cerebelo direito e o giro frontal médio direito apresentaram um volume maior de corpos celulares de neurônios (Ruocco \& Carcone, 2016). À vista disso, futuros estudos são necessários para compreender se ocorre uma diferenciação em mais áreas, se os achados são patognomônicos do transtorno e quais as influências dessas modificações para os indivíduos com o transtorno.

\subsection{Epigenética e Transtorno de Personalidade Borderline (TPB)}

As alterações epigenéticas, em grande maioria, possuem a função de garantir o controle homeostático a acessibilidade gênica e a funcionalidade transcricional (Gescher et al. 2018). Essa maquinaria consiste em três mecanismos: modificação das histonas, alterações no RNA e no microRNA e aumento da metilação da citosina em locais CpG (Gescher et al., 2018; Tescher et al. 2013). Regiões do DNA ricas em CG e CpG - nucleotídeo de citosina seguido por um nucleotídeo de guanina na 
sequência 5'3'- onde metilações regulatórias do DNA ocorrem, principalmente, na citosina de um dinucleotídeo CpG, quando mais metiladas, são chamadas de ilhas CpG (Dammannn et al., 2011; Knoblich et al., 2017). Hipermetilação de locais CpG nas regiões promotoras, em geral, inibem a transcrição genética, por outro lado, no corpo do gene, comumente resultam em uma expressão aumentada. Por fim, 259 sites CpG significantemente metilados foram descobertos (Knoblich et al., 2017).

A maioria dos estudos focam na análise de genes candidatos e pequenas amostras, com resultados incapazes de explicar a patogênese do transtorno. Apenas dois estudos utilizaram a associação de genoma (GWAS) obtendo alguns sinais promissores. Ademais, encontrou-se uma sobreposição genética do TPB com Transtorno Bipolar, Transtorno Depressivo Maior e Esquizofrenia (Bulbelna-Cabre, Bassir Nia, Perez-Rodriguez, 2018).

A maioria das anormalidades epigenéticas relacionadas ao TPB concentram seus genes relacionados ao estresse, neurodesenvolvimento e a condições neuropsiquiátricas (Bassir Nia et al., 2018). Os principais genes sugeridos que apresentaram algum envolvimento com o transtorno foram: MAOA, MAOB, NRC31, BDNF, APBA2, APBA3, KCNQ1, MCF2, NINJ2, PRIMA1, COMT (Val108/158Met), HTR2A, 5-HTT, FKBP5, OXTR-rs53576.

Ambos os genes que codificam a Monoamina oxidase A (MAOA) e Monoamina oxidase B (MAOB) se localizam no braço curto do cromossomo X e estão relacionados com o metabolismo de monoaminas. Relataram-se metilações aberrantes em cinco locais $\mathrm{CpG}$ no gene promotor MAOA, em especial no sítio $\mathrm{CpG} 4$, e em um local $\mathrm{CpG}$ (CpG5) para o gene promotor MAOB, ainda foi apontado um processo de metilação dimórfica entre gêneros, na qual os valores médios para homens se mostraram significativamente menores. Para mulheres, esses níveis foram mais elevados (Dammann et al., 2011; Ziegler \& Domschke, 2018). Dammann et al. (2011) correlacionaram o aumento da quantidade de neurotransmissores monoamínicos com o aumento da metilação de MAOA e MAOB, que por sua vez, provocaria uma inativação transcricional, e assim, redução dos níveis de monoamina oxidase.

Houve uma correlação entre hipermetilação de NR3C1 nos sítios CpG1 e CpG5 em cérebros pós-morte e uma menor expressão de mRNA do receptor glicocorticoide (GR) com exposição a adversidades no início da vida e TPB (Dammann et al., 2011; Gescher et al., 2018). O gene promotor BDNF (Fator neurotrófico derivado do cérebro), um neuropeptídeo com papel importante no neurodesenvolvimento e neuroplasticidade, exprimiu hipermetilação para os pacientes TPB e influência na manifestação da sintomatologia relacionada ao impulso agressivo observado no transtorno. (Bulbelna-Cabre et al., 2018).

Ao codificar proteínas adaptadoras neuronais, investigou-se um aumento na metilação em até 1,1 vezes nos locais CpG de APBA2 e APBA3 (Família de Ligação de Proteína Precursora Beta Amiloide 2 e Família de Ligação de Proteína Precursora Beta Amiloide 3, respectivamente) (Bulbelna-Cabre et al., 2018). A partir da análise dos níveis reduzidos de metilação de APBA2 e APBA3, correlacionando-os com o aumento nos níveis de mRNA desses mesmos genes, Dammann et al. (2011) propuseram uma relação entre diferenças na metilação do DNA e expressão diferencial desses respectivos genes.

Distúrbios nos genes do sistema serotonérgico - HTR2A e 5-HTTLPR - são fortes candidatos por estarem associados aos principais mecanismos que podem gerar ou ampliar a sintomatologia do TPB, metilações aberrantes foram relatadas nesses genes na maioria dos estudos selecionados. Um aumento da metilação do promotor PRIMA1 em amostras de sangue periférico e uma diminuição dos níveis de metilação do promotor distal 5 'região ETS do rDNA em pacientes TPB foi relatado por Tescher, Gotthardt, Dammann \& Dammann (2016). Os genes KCNQ1 - proteína do canal de potássio controlado por voltagem - MCF2, NINJ2 (proteína induzida por lesão nervosa, NINJURIN2), COMT - envolvido na degradação de catecolaminas apresentaram, respectivamente, aumento da metilação em 1,5, 1,1, 1,2 e 1,07 vezes (Tescher et al., 2013; Thomas et al., 2019). COMT apresenta duas isoformas, uma ligada a membrana dos tecidos do sistema nervoso central, MB-COMT - essa forma no cérebro de pacientes TPB é significativamente hipometilada - e outra solúvel nos tecidos periféricos, S-COMT. As análises acerca da metilação são realizadas a partir de fluídos e sangue periférico, portanto, apenas o S-COMT é plausível de análise in vivo, apresentando metilação aumentada nos sítios CpG 1 e CpG 2 (Dammann et al., 2011; Thomas et al., 2019). 
Metilações aberrantes relatadas no gene promotor de oxitocina (OXTR-rs53576) vão de acordo com a hipótese de suscetibilidade diferencial, a qual postula uma diferença na herdabilidade do transtorno. Já no haplótipo FKBA5 CATT, com funções no sistema límbico, não só um aumento na metilição foi relatada, como também uma sintomatologia foi apresentada de maneira diferente quanto ao gênero; isto é, sintomas aumentados em mulheres e diminuídos em homens, quando expostos a maus tratos no início da vida (Bulbelna-Cabre et al., 2018).

Os estudos que utilizaram associação de genoma (GWAS) se depararam com sinais promissores no cromossomo $\mathrm{S}$ correspondendo a SERINC5, uma proteína participante da mielinização, e com dois genes significativos: (1) dihidropirimidina desidrogenase (DPYD) no cromossomo 1 e (2) plakofilena-4 (PKP4) no cromossomo S. (Bulbelna-Cabre et al. 2018). Apesar dos vários achados e dos inúmeros genes candidatos, os estudos não conseguiram traçar uma patogênese plausível, revelando, assim, a necessidade de uma abordagem diferente, com enfoque no método GWAS para garantir resultados mais coerentes e que, de fato, poderão elucidar a etiologia do Transtorno de Personalidade Borderline.

\subsection{Trauma Infantil e Transtorno de Personalidade Borderline (TPB)}

O trauma na infância é considerado o principal fator ambiental envolvido no TPB (Martin-Blanco et al., 2014), estudos apontam uma correlação entre as adversidades precoces com a expressão sintomatológica do transtorno e sua gravidade (Elices et al., 2015). Dentre os tipos de maus-tratos infantis inclui-se abuso físico, abuso emocional, abuso sexual, negligência emocional e negligência física, compreendendo taxas de experiências precoces traumáticas entre 30 a $90 \%$ dos casos (Elices et al., 2015). A compreensão dos efeitos desses eventos traumáticos para o tratamento da psicopatologia e as suas influências seja na patogênese ou na manifestação dos sintomas ainda é limitada (Euler et al., 2019), necessitando, assim de novas investigações acerca das influências do trauma infantil no Transtorno de Personalidade Borderline.

As taxas de abuso sexual, abuso físico, abuso emocional, negligência emocional e negligência física apresentam, percentuais, respectivamente entre: 40 a 70\%; 25 a 73\%; 13 a 76\%; 51\% e 26 a 35\% (Elices et al., 2015; Euler et al., 2019; Martin-Blanco et al., 2014). Martin-Blanco et al. (2015a) sugeriu a contribuição de variantes genéticas sob efeito modulador do trauma infantil e a manifestação dos sintomas, após isso, algumas hipóteses foram propostas como a associação entre o alelo curto de um polimorfismo na região promotora SCL6A4 e a impulsividade, relação entre a variante COMT Val158met e a agressividade e disfunções no eixo HPA moduladas por experiencias precoces de trauma (Martin-Blanco et al., 2015b), todavia, nenhum polimorfismo ou gene concreto ou evento específico foi constatado como característico da psicopatologia.

McFetridge et al. (2015) relata que o abuso sexual na infância é preditivo de Transtorno de Personalidade em todas as culturas, enquanto Parker, McCraw e Beyes (2018) expõem associação entre pacientes TPB que sofreram abuso sexual na infância com instabilidade afetiva e "sentimentos dolorosos de incoerência de identidade", eles também expuseram correlação entre distúrbios de identidade com trauma de desenvolvimento não relacionado ao abuso sexual infantil. Mulheres TPB frequentemente relatam ambientes familiares na infância altamente patogênicos (Laporte et al., 2011), somado a isso, elas configuram 85\% dos casos do Transtorno de Personalidade Borderline diagnosticados (Martin-Blanco et al. 2014), não se acredita ser por uma questão de gênero, mas sim social, em que as mulheres apresentam maiores cuidados com a saúde (Skodol, 2020). Mais um agravante publicado por Sinai et al. (2014) apontou que pacientes TPB do sexo feminino expostas a violência interpessoal severa na infância exprimem uma razão negativa entre os hormônios tireoidianos, ou seja, uma desiodação periférica reduzida.

Estudos epidemiológicos sugerem correspondência entre adversidades na infância e uma probabilidade aumentada de TPB (Euler et al., 2019), além disso há uma tendencia dos indivíduos TPB com histórico de maus-tratos nos anos iniciais da vida de manifestarem automutilação, sintomas dissociativos, distúrbios emocionais, psicose e angústia global de maneira mais grave comparado com aqueles que não sofreram na puerícia (Euler et al., 2019). Ademais, os diferentes traços de 
personalidade influenciam em como as pessoas reagem a situações de abuso e/ou negligência e isso interfere na desenvolução do transtorno, uma vez que a sensibilidade temperamental - níveis aumentados de emocionalidade e impulsividade colaboram para a gênese da psicopatologia (Laporte et al., 2011). Outro fator de influência se concentra nos relacionamentos parentais, em especial, nos disfuncionais, ao utilizar Parental Bonding Instrument para analisar esse tipo de relação, constataram-se atitudes maternas perturbadas, falhas paternas e, em grande maioria, falha biparental, entre pais e filhos com TPB (Laporte et al., 2011), não ficando claro se apenas uma das partes apresentava o TPB, ou se ambos tinham o transtorno, em contrapartida, comprovou-se que $14,9 \%$ das crianças abusadas/negligenciadas identificadas com TPB na fase adulta possuíam pais com Transtornos por uso de substancias, Transtorno Depressivo Maior ou Transtorno de Estresse Póstraumático (Martin-Blanco et al., 2014). Corrobora-se, portanto que apenas a exposição a fatores de risco ambientais não implica no surgimento do transtorno, isto posto, faz-se necessária uma combinação de diáteses e estressores para a etiologia do TPB (Laporte et al., 2011), e que há uma influência do trauma infantil na patogênese e na expressão da sintomatologia do transtorno.

\section{Considerações Finais}

Em relação ao papel do trauma da infância na etiologia do TPB, tendo em vista o fato de a maioria dos estudos sobre TPB e trauma infantil terem averiguado a presença ou ausência de eventos traumáticos com base na autodeclaração, são necessários mais estudos sobre essa temática com a inclusão do histórico documentado dos pacientes, a fim de se garantir a veracidade dos fatos, e de se constar, em registro, a influência que o abuso/negligência possui no desenvolvimento do transtorno.

Sobre o papel da neurobiologia na etiologia do transtorno, perante a heterogeneidade dos estudos e os obstáculos para se encontrar resultados confiáveis, percebe-se a necessidade de averiguar os atuais achados e iniciar novos estudos com o intuito de desvendar se as anormalidades neurobiológicas estão correlacionadas a etiologia do transtorno ou se são efeitos decorrentes da psicopatologia. Já na epigenética, mais estudos GWAS são indispensáveis, com o propósito de se compreender quais genes endofenótipos estão envolvidos na origem do transtorno. Evidencia-se, portanto, que achados importantes foram relatados nas três áreas de pesquisa - neurobiologia, epigenética e trauma infantil - consistindo com a teoria etiológica que correlaciona as interações entre gene e ambiente; ou seja, futuros estudos não devem apenas se aprofundar separadamente nesses grupos de conhecimento, mas, sim, interligá-los em uma tarefa multidisciplinar capaz de explicar, por completo, as bases etiológicas do Transtorno de Personalidade Borderline.

\section{Referências}

American Psychiatric Association (2014). Manual diagnóstico e estatístico de transtornos mentais: DSM-5. (5a ed.); M. I. C. Nascimento, Trad.) Artmed.

Bassir Nia, A., Eveleth, M. C., Gabbay, J. M., Hassan, Y. J., Zhang, B., \& Perez-Rodriguez, M. M. (2018). Past, present, and future of genetic research in borderline personality disorder. Current opinion in psychology, 21, 60-68. https://doi.org/10.1016/j.copsyc.2017.09.002

Bulbena-Cabre, A., Bassir Nia, A., \& Perez-Rodriguez, M. M. (2018). Current Knowledge on Gene-Environment Interactions in Personality Disorders: An Update. Current psychiatry reports, 20(9), 74. https://doi.org/10.1007/s11920-018-0934-7

Chanen, A. M., \& Kaess, M. (2012). Developmental pathways to borderline personality disorder. Current psychiatry reports, 14(1), 45-53. https://doi.org/10.1007/s11920-011-0242-y

Dammann, G., Teschler, S., Haag, T., Altmüller, F., Tuczek, F., \& Dammann, R. H. (2011). Increased DNA methylation of neuropsychiatric genes occurs in borderline personality disorder. Epigenetics, 6(12), 1454-1462. https://doi.org/10.4161/epi.6.12.18363

Elices, M., Pascual, J. C., Carmona, C., Martín-Blanco, A., Feliu-Soler, A., Ruiz, E., Gomà-I-Freixanet, M., Pérez, V., \& Soler, J. (2015). Exploring the relation between childhood trauma, temperamental traits, and mindfulness in borderline personality disorder. BMC psychiatry, 15 , 180 . https://doi.org/10.1186/s12888-015-0573-z 
Euler, S., Stalujanis, E., Lindenmeyer, H. J., Nicastro, R., Kramer, U., Perroud, N., \& Weibel, S. (2019). Impact of Childhood Maltreatment in Borderline Personality Disorder on Treatment Response to Intensive Dialectical Behavior Therapy. Journal of personality disorders, 1-19. Advance online publication. https://doi.org/10.1521/pedi_2019_33_461

Gescher, D. M., Kahl, K. G., Hillemacher, T., Frieling, H., Kuhn, J., \& Frodl, T. (2018). Epigenetics in Personality Disorders: Today's Insights. Frontiers in psychiatry, 9, 579. https://doi.org/10.3389/fpsyt.2018.00579

Guendelman, S., Garay, L., \& Miño, V. (2014). Neurobiología del trastorno de personalidad límite [Neurobiology of borderline personality disorder]. Revista médica de Chile, 142(2), 204-210. https://doi.org/10.4067/S0034-98872014000200009

Goodman, M., Mascitelli, K., \& Triebwasser, J. (2013). The Neurobiological Basis of Adolescent-onset Borderline Personality Disorder. Journal of the Canadian Academy of Child and Adolescent Psychiatry = Journal de l'Academie canadienne de psychiatrie de l'enfant et de l'adolescent, 22(3), $212-219$.

Knoblich, N., Gundel, F., Brückmann, C., Becker-Sadzio, J., Frischholz, C., \& Nieratschker, V. (2018). DNA methylation of APBA3 and MCF2 in borderline personality disorder: Potential biomarkers for response to psychotherapy. European neuropsychopharmacology: the journal of the European College of Neuropsychopharmacology, 28(2), 252-263. https://doi.org/10.1016/j.euroneuro.2017.12.010

Laporte, L., Paris, J., Guttman, H., \& Russell, J. (2011). Psychopathology, childhood trauma, and personality traits in patients with borderline personality disorder and their sisters. Journal of personality disorders, 25(4), 448-462. https://doi.org/10.1521/pedi.2011.25.4.448

Leichsenring, F., Leibing, E., Kruse, J., New, A. S., \& Leweke, F. (2011). Borderline personality disorder. Lancet (London, England), 377(9759), 74-84. https://doi.org/10.1016/S0140-6736(10)61422-5

Martín-Blanco, A., Soler, J., Villalta, L., Feliu-Soler, A., Elices, M., Pérez, V., Arranz, M. J., Ferraz, L., Alvarez, E., \& Pascual, J. C. (2014). Exploring the interaction between childhood maltreatment and temperamental traits on the severity of borderline personality disorder. Comprehensive psychiatry, 55(2), 311-318. https://doi.org/10.1016/j.comppsych.2013.08.026

Martín-Blanco, A., Ferrer, M., Soler, J., Arranz, M. J., Vega, D., Bauzà, J., Calvo, N., Elices, M., Sanchez-Mora, C., García-Martinez, I., Salazar, J., Ribases, M., Carmona, C., Prat, M., \& Pascual, J. C. (2015a). An exploratory association study of the influence of noradrenergic genes and childhood trauma in Borderline Personality Disorder. Psychiatry research, 229(1-2), 589-592. https://doi.org/10.1016/j.psychres.2015.07.046

Martín-Blanco, A., Ferrer, M., Soler, J., Arranz, M. J., Vega, D., Calvo, N., Elices, M., Sanchez-Mora, C., García-Martinez, I., Salazar, J., Carmona, C., Bauzà, J., Prat, M., Pérez, V., \& Pascual, J. C. (2015b). The role of hypothalamus-pituitary-adrenal genes and childhood trauma in borderline personality disorder. European archives of psychiatry and clinical neuroscience, 266(4), 307-316. https://doi.org/10.1007/s00406-015-0612-2

McFetridge, M. A., Milner, R., Gavin, V., \& Levita, L. (2015). Borderline personality disorder: patterns of self-harm, reported childhood trauma and clinical outcome. BJPsych open, 1(1), 18-20. https://doi.org/10.1192/bjpo.bp.115.000117

Parker, G., McCraw, S., \& Bayes, A. (2018). Borderline personality disorder: does its clinical features show specificity to differing developmental risk factors? Australasian psychiatry: bulletin of Royal Australian and New Zealand College of Psychiatrists, 26(4), 410-413. https://doi.org/10.1177/1039856218760732

Pereira A.S. et al. (2018). Metodologia da pesquisa científica. UFSM.

Ruocco, A. C., \& Carcone, D. (2016). A Neurobiological Model of Borderline Personality Disorder: Systematic and Integrative Review. Harvard review of psychiatry, 24(5), 311-329. https://doi.org/10.1097/HRP.0000000000000123

Sinai, C., Hirvikoski, T., Nordström, A. L., Nordström, P., Nilsonne, A., Wilczek, A., Asberg, M., \& Jokinen, J. (2014). Hypothalamic pituitary thyroid axis and exposure to interpersonal violence in childhood among women with borderline personality disorder. European journal of psychotraumatology, 5 , 10.3402/ejpt.v5.23911. https://doi.org/10.3402/ejpt.v5.23911

Skodol, A. (2020). Borderline personality disorder: Epidemiology, pathogenesis, clinical features, course, assessment, and diagnosis. UpToDate. https://www.uptodate.com/contents/borderline-personality-disorder-epidemiology-thogenesis-clinical-features-course-assessment-and-

diagnosis?search=transtorno $\% 20 \mathrm{de} \% 20$ personalidade $\% 20 \mathrm{lim} \% \mathrm{C} 3 \%$ ADtrofe \&source=search_result\&selectedTitle=1 72\&usage_type=default\&display_rank= 1

Teschler, S., Bartkuhn, M., Künzel, N., Schmidt, C., Kiehl, S., Dammann, G., \& Dammann, R. (2013). Aberrant methylation of gene associated CpG sites occurs in borderline personality disorder. PloS one, 8(12), e84180. https://doi.org/10.1371/journal.pone.0084180

Teschler, S., Gotthardt, J., Dammann, G., \& Dammann, R. H. (2016). Aberrant DNA Methylation of rDNA and PRIMA1 in Borderline Personality Disorder. International journal of molecular sciences, 17(1), 67. https://doi.org/10.3390/ijms17010067

Thomas, M., Banet, N., Wallisch, A., Glowacz, K., Becker-Sadzio, J., Gundel, F., \& Nieratschker, V. (2019). Differential COMT DNA methylation in patients with Borderline Personality Disorder: Genotype matters. European neuropsychopharmacology: the journal of the European College of Neuropsychopharmacology, 29(11), 1295-1300. https://doi.org/10.1016/j.euroneuro.2019.09.011

Van Heel, M., Luyten, P., De Meulemeester, C., Vanwalleghem, D., Vermote, R., \& Lowyck, B. (2019). Mentalizing Based on External Features in Borderline Personality Disorder Compared with Healthy Controls: The Role of Attachment Dimensions and Childhood Trauma. Journal of personality disorders, 33(6), 736-750. https://doi.org/10.1521/pedi_2019_33_373

Ziegler, C., \& Domschke, K. (2018). Epigenetic signature of MAOA and MAOB genes in mental disorders. Journal of neural transmission (Vienna, Austria: 1996), 125(11), 1581-1588. https://doi.org/10.1007/s00702-018-1929-6

Wingenfeld, K., Spitzer, C., Rullkötter, N., \& Löwe, B. (2010). Borderline personality disorder: hypothalamus pituitary adrenal axis and findings from neuroimaging studies. Psychoneuroendocrinology, 35(1), 154-170. https://doi.org/10.1016/j.psyneuen.2009.09.014na 